\title{
PENGARUH KESEJAHTERAAN KARYAWAN BERSIFAT EKONOMI TERHADAP TURNOVER INTENTION PADA PT. ARINA MULTIKARYA SAMARINDA
}

\author{
Regita Maulidya Putri' ${ }^{1}$ Fenty Fauziah ${ }^{2}$ \\ 1,2 Fakultas Ekonomi, Hukum, Politik dan Psikologi \\ Universitas Muhammadiyah Kalimantan Timur, Kaltim, Indonesia \\ *corresponding author: regitamp17@gmail.com
}

\begin{abstract}
ABSTRAK
Penelitian ini dilakukan guna menguji dan menganalisis dampak kesejahteraan karyawan yang bersifat ekonomi terhadap turnover intention pada PT. Arina Multikarya Samarinda. Pembagian kuesioner kepada 151 karyawan untuk mengumpulkan data. Metode kuantitatif dengan menggunakan bantuan SPSS. Teknik pengambilan data yang dipakai adalah metode kuesioner, teknik analisis yang digunakan dalam penelitian ini menggunakan uji validitas, uji reliabilitas, analisis regresi linier sederhana. Hasil yang ditemukan adalah terdapat Pengaruh antara Kesejahteraan Karyawan Bersifat Ekonomi Terhadap Turnover Intention Pada PT. Arina Multikarya Samarinda. Ini dapat terlihat pada hasil yang ditemukan bahwa semakin tinggi tingkat ekonomi kerja, maka semakin tinggi juga semangat kerja karyawan sehingga memperkecil dampak Turnover. Penelitian ini dapat menjadi referensi bagi peneliti selanjutnya bahkan pada PT. Arina Multikarya Samarinda khususnya untuk lebih melihat faktor-faktor lain yang mempengaruhi turnover intention, karena sangat penting untuk keberlangsungan sebuah perusahaan.
\end{abstract}

Kata Kunci: Produk Domestik Bruto, Kesejahteraan Karyawan, Turnover Intention

\section{ABSTRACT}

This research was conducted to test and analyze the impact of economic welfare of employees on turnover intention at PT. Arina Multikarya Samarinda. Distribution of questionnaires to 151 employees to collect data. Quantitative method using SPSS assistance. The data collection technique used was a questionnaire method, the analysis technique used in this study used a validity test, a reliability test, a simple linear regression analysis. The results found are that there is an Influence between Economic Welfare of Employees Against Turnover Intention at PT. Arina Multikarya Samarinda. This can be seen in the results found that the higher the level of work economy, the higher the employee morale so that it reduces the impact of Turnover. This research can be a reference for further researchers even at PT. Arina Multikarya Samarinda especially to look more at other factors that influence turnover intention, because it is very important for the sustainability of a company.

Keywords : Gross Domestic Product, Employee Welfare, Turnover Intention 


\section{PENDAHULUAN}

Kesejahteraan ekonomi karyawan selalu berorientasi pada penghasilan yang didapat dari perusahaan tempat mereka bekerja dengan tujuan agar bisa mendukung kondisi ekonomi karyawan tersebut dengan kata lain semakin besar hasil atau pendapatan untuk menunjang kondisi ekonomi dan kesejahteraan hidup karyawan maka akan membuat karyawan menjadi tetap betah untuk bekerja di perusahaan tersebut.

Kesejahteraan ekonomi pada karyawan yang terjadi pada perekrutan karyawan inilah yang membuat peneliti mengaitkan kasusnya pada PT Arina Multi karya Samarinda semangat kerja yang ada pada karyawan dipengaruhi oleh kesejahteraan yang berupa ekonomis.

Peran kesejahteraan ekonomi yang diberikan untuk tenaga kerja bertujuan untuk memotivasi kedisiplinam tenaga kerja, semangat kerja karyawan yang menciptakan motivasi karyawan untuk memberikan ide kepada perusahaan agar lebih maju untuk ke depannya dan karyawan mempunyai sikap loyal terhadap perusahaan.

Secara empiris kesejahteraan yang bersifat ekonomis dipengaruhi oleh beberapa hal dalam menunjang kompetensi kerja seorang karyawan seperti tujuan seorang karyawan dalam mencari lapangan kerja adalah mengharapkan imbalan atau upah yang sesuai yang bersifat ekonomis merupakan hak sebagai karyawan.

Salah satu tujuan dalam mencari sebuah pekerjaan adalah mencari kesejahteraan yang bersifat ekonomis atau gajih sehingga hal ini menjadi salah satu daftar yang paling penting bagi karyawan untuk memotivasi seorang karyawan agar lebih semangat bekerja. Kesejahteraan karyawan yang bersifat ekonomis merupakan salah satu tujuan bagi seorang pekerja dalam mencari kesejahteraan di lingkungan kerja sehingga hal ini merupakan salah satu penyebab banyaknya karyawan yang keluar masuk dalam sebuah perusahaan seperti pada kasus-kasus yang ada saat ini.

Salah satu tujuan dalam mencari pekerjaan untuk menunjang kesejahteraan ekonomi kehidupan karyawan yang bersifat gajih atau penghasilan sehingga dalam hal ini akan menjadi salah satu yang memotivasi Seorang karyawan untuk memilih bekerja di suatu tempat atau mencari pekerjaan lain hal inilah yang menjadi dasar pengaitan dan meningkatkan kesejahteraan bagi para karyawan.

PTArina Multikarya Samarinda merupakan salah satu perusahaan outshorching yang ada di Samarinda dan merupakan salah satu perusahaan yang jasanya banyak digunakan oleh perusahaan-perusahaan besar di Indonesia dan dalam kasusnya banyak yang masuk dalam TurnoverIntention sehingga peneliti berfikir untuk mengangkat objek tersebut.

Menurut Siagian (2012), yakni "kesejahteraan karyawan merupakan biaya sampingan pemberian pelayanan kesehatan kepada para karyawan berupa asuransi bersama, asuransi kesehatan, asuransi gigi, asuransi kematian, asuransi kecelakaan”. 
Dari uraian di atas maka dapat disimpulkan bahwa kesejahteraan ekonomi karyawan sangat penting untuk kebutuhan setiap karyawan karna berpengaruh pada kehidupan sosial mereka seperti uang kesehatan/asuransi, bonus, tunjangan dll.

\section{Turnover Intention}

Turnover intention yaitu merupakan kecenderungan atau intensitas individu untuk meninggalkan organisasi dengan berbagai alasan dan diantaranya keinginan untuk mendapatkan pekerjaan yang lebih baik (Ronald dan Milkha, 2014).

Turnover intention adalah kecenderungan atau keinginan berkelanjutan yang dilakukan oleh karyawan untuk meninggalkan organisasi dan digantikan kembali oleh karyawan lain. Hal ini sering dijadikan sebagai indikator kinerja perusahaan sehingga terlihat efektivitas dan efisiensi organisasi yang negatif (Samuel dan Ikemefuna, 2012).

Menurut Rivai (2009),Turnover intention merupakan keinginan karyawan untuk berhenti kerja dari perusahaan secara sukarela atau pindah dari satu tempat ke tempat kerja yang lain menurut pilihannya sendiri. Perputaran (turnover) dikelompokkan ke dalam beberapa cara yang berbeda antara lain:

a. Perputaran secara tidak sukarela: jadi berupa pemecatan (PHK) karena kinerja yang buruk dan pelanggaran peraturan kerja.

b. Perputaran secara sukarela dimana karyawan meninggalkan perusahaan karena keinginannya sendiri. 


\section{Peneliti Terdahulu}

Tabel 1 :Penelitian Terdahulu

\begin{tabular}{|c|c|c|c|c|c|}
\hline No & Peneliti & Judul & Variabel & $\begin{array}{c}\text { Metode Yang } \\
\text { Digunakan }\end{array}$ & Hasil Penelitian \\
\hline 1 & $\begin{array}{l}\text { Amelia } \\
(2010)\end{array}$ & $\begin{array}{l}\text { Work-To- } \\
\text { Family Conflict } \\
\text { dan Family-To- } \\
\text { Work Conflict } \\
\text { terhadap } \\
\text { Kepuasan } \\
\text { dalam Bekerja, } \\
\text { Keinginan } \\
\text { Pindah Tempat } \\
\text { Kerja dan } \\
\text { Kinerja } \\
\text { Karyawan. }\end{array}$ & $\begin{array}{l}\text { Work to } \\
\text { family } \\
\text { conflict }(\mathrm{X} 1) \\
\text { Family to } \\
\text { work conflict } \\
\text { (X2) } \\
\text { Kepuasan } \\
\text { (X3) } \\
\text { keinginan } \\
\text { (X4) } \\
\text { Kinerja (Y) }\end{array}$ & $\begin{array}{l}\text { Regresi linier } \\
\text { berganda }\end{array}$ & $\begin{array}{l}\text { Work-To-Family Conflict } \\
\text { dan Family-To-Family } \\
\text { Conflict mempunyai } \\
\text { hubungan negatif terhadap } \\
\text { Kepuasan dalam Bekerja } \\
\text { dan Kinerja Karyawan } \\
\text { sedangkan Work-To- } \\
\text { Family Conflict dan } \\
\text { Work-To-Family Conflict } \\
\text { mempunyai hubungan } \\
\text { positif terhadap Keinginan } \\
\text { Pindah Tempat Bekerja }\end{array}$ \\
\hline
\end{tabular}

$\begin{array}{lllll}\text { Fajar } & \text { Pengaruh infalsi } & \text { Infalsi (X1) } & \text { Regresi Linier } & \text { Variabel Upah } \\ \text { Wahyu } & \text { dan upah } & \text { Upah (X2) } & \text { Sederhana } & \text { mempunyai pengaruh } \\ \text { Utomo } & \text { terhadap } & \text { Penganggura } & & \text { yang signifikan terhadap } \\ \text { (2013) } & \begin{array}{l}\text { pengangguran } \\ \text { di indonesia }\end{array} & \text { n (Y) } & & \text { pengangguran diindonesia } \\ & & & \text { dan variabel inflasi tidak } \\ & & & \text { berpengaruh terhadap } \\ & & & \text { pengangguran. }\end{array}$

\begin{tabular}{lllll}
\hline 3 Puspitasari & Pengaruh & Konflik & Regresi linier & Konflik Kerja-Keluarga \\
(2012) & Konflik & pekerjaan & berganda & $\begin{array}{l}\text { berpengaruh negatif dan } \\
\text { signifikan terhadap }\end{array}$ \\
& Pekerjaan & (X1) & & Komitmen Organisasi dan \\
& Keluarga & Komitmen & & Kepuasan Kerja \\
& terhadap & organisasi & & sedangkan Kepuasan \\
& Komitmen & (X2) & & Kerja berpengaruh positif \\
& Organisasi & Kepuasan & & dan signifikan terhadap \\
& dengan & kerja $(Y)$ & & Komitmen Organisasi \\
& Kepuasan Kerja & &
\end{tabular}




\begin{tabular}{|c|c|c|c|c|c|}
\hline 4 & $\begin{array}{l}\text { Ni } \\
\text { Nyoman } \\
\text { Setya Ari } \\
\text { Wijayanti } \\
\text { danNi Luh } \\
\text { Karmini } \\
(2014)\end{array}$ & $\begin{array}{l}\text { Pengaruh } \\
\text { Tingkat Inflasi, } \\
\text { Laju } \\
\text { Pertumbuhan } \\
\text { ekonomi dan } \\
\text { Upah minimum } \\
\text { Terhadap } \\
\text { Tingkat } \\
\text { Pengangguran } \\
\text { Terbuka Di } \\
\text { Provinsi Bali }\end{array}$ & $\begin{array}{l}\text { Tingkat } \\
\text { inflasi (X1) } \\
\text { Pertumbuhan } \\
\text { ekonomi } \\
(\mathrm{X} 2) \\
\text { Upah (X3) } \\
\text { Tingkat } \\
\text { penganggura } \\
\text { n (Y) }\end{array}$ & $\begin{array}{l}\text { Metode } \\
\text { asosiatif } \\
\text { teknik análisis } \\
\text { regresi data }\end{array}$ & $\begin{array}{l}\text { Pertumbuhan ekonomi } \\
\text { dan upah minimum } \\
\text { memiliki pengaruh secara } \\
\text { simultan dan signifikan } \\
\text { terhadap tingkat } \\
\text { pengangguran terbuka di } \\
\text { provinsi bali, sedangkan } \\
\text { hasil ujiparsial diperoleh } \\
\text { bahwa tingkat inflasi dan } \\
\text { upah minimum memiliki } \\
\text { pengaruh yang negatif dan } \\
\text { signifikan dengan tingkat } \\
\text { pengangguran terbuka di } \\
\text { provinsi bali, } \\
\text { sedangankan tingkat } \\
\text { pertumbuhan ekonomi } \\
\text { tidah berpengaruh } \\
\text { terhadap tingkat } \\
\text { pengangguran terbuka di } \\
\text { provinsi bali. }\end{array}$ \\
\hline
\end{tabular}

\begin{tabular}{lllll}
\hline Alex Bayu & Pengaruh & Variabel & Penelitian & Secara simultan variabel \\
Sahari & Kompensasi & komunikasi & penjelas & komunikasi persuasif \\
$(2009)$ & Non Finansial & Persuasif (X) & (explanatory & pengaruh yang cukup \\
& Terhadap & yang terdiri & research) & kuat, dan jika dilihat dari \\
& Motivasi Kerja & dari imbalan & dengan & Adjusted $R$ Square maka \\
& Karyawan Di & Karir (X1), & pendekatan & variabel komunikasi \\
& Perusahaan & dan Imbalan & kuantitatif & persuasif mempunyai \\
& Rodeo - & Sosial (X2), & & pengaruh yang cukup \\
& Lawang & Motivasi & & besar juga terhadap \\
& & Kerja (Y) & kinerja
\end{tabular}




\section{Kerangka Pikir}

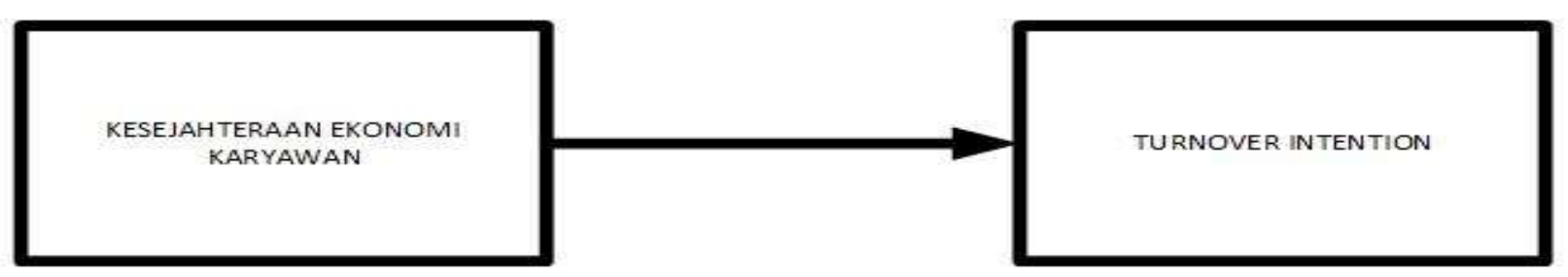

Gambar 1 : Kerangka Pikir

\section{Hipotesis}

Ho:Tidak terdapat pengaruh antara Kesejahteraan Ekonomi Karyawan terhadapTurnover Intentionpada PT.Arina MultiKarya Samarinda.

Ha:Terdapat Pengaruh antara Kesejahteraan Ekonomi Karyawan terhadap Turnover Intentionpada PT.Arina MultiKarya Samarinda.

\section{METODE PENELITIAN}

Penelitian ini dilakukan pada PT Arina Multikarya yang ada di JL. H Adam Malik No. 10 RT. 01 Kel. Karang Asam Kec. Sungai Kunjang Samarinda. Berdasarkan dari data yang diperoleh jumlah karyawan yang ada pada PT Arina Multikarya berjumlah 242 orang karyawan, teknik pengambilan sampel yang digunakan adalah simple random sampling dengan jumlah 151 sempel 151 orang yang diperoleh dari banyaknya jumlah populasi. Teknik pengumpulan data yang digunakan adalah dengan menyebar kuesioner ke setiap responden penelitian melalui google form, serta dengan menggunakan teknik analisis regresi linier sederhana berdasarkan loading analysis output SPSS 23 dan dengan menggunakan rumus teknik pengambilan sampel sebagai berikut:

$$
n=\frac{N}{1+N(e)^{2}}
$$

Keterangan :

$\mathrm{n} \quad=$ Jumlah sampel yang diperlukan

$\mathrm{n} \quad=$ Jumlah Populasi

e =Tingkat kesalahan sampel (sampling eror), biasanya ditetapkan $1 \%$ atau $5 \%$

\section{Teknik Pengumpulan Data}

Teknik pengumpulan data yang kami gunakan pada penelitian ini adalah teknik kuesioner, kami menggunakan teknik pengumpulan data dengan kuesioner karena kami merasa bahwa teknik adalah salah satu cara yang cukup simpel dan mudah untuk diaplikasikan apalagi bagi para mahasiswa yang bekerja sambil kuliah. 


\section{Uji Validitas}

Validitas berasal dari kata validity yang mempunyai arti sejauh mana ketepatan dan kecermatan suatu alat ukur dalam melakukam fungsi ukurannya (Azwar 2011). Selain itu validitas adalah suatu ukuran yang menunjukkan bahwa. Variabel yang diukur memang benar-benar variabel yang hendak diteliti oleh peneliti.Sedangkan untuk mengetahui valid tidaknya suatu item instrument dapat diketahui dengan membandingkan indeks Korelasi Product Moment atau $\mathrm{r}$ hitung dengan nilai kritisnya dan rumus product moment yang digunakan adalah sebagai berikut

Rumus :

$$
\begin{gathered}
\mathrm{r}=\mathrm{n}\left(\sum x y\right)-\left(\sum x \cdot \sum y\right) \\
\sqrt{\left(n\left(\sum x^{2}\right)-\left(\sum x\right)^{2}\left(n\left(\sum y^{2}\right)-\left(\sum y\right)^{2}\right)\right.}
\end{gathered}
$$

Keterangan :

rxy =Koefisien korelasi antara variable $\mathrm{X}$ dan $\mathrm{Y}$

$\sum x y=J u m l a h$ perkalian antara variable $X$ dan $Y$

$\sum \times 2=$ Jumlah dari kuadrat nilai $\mathrm{X}$

$\sum$ y2 =Jumlah kuadrat dari nilai Y

$\left(\sum x\right) 2=J u m l a h$ nilai $X$ kemudian dikuadratkan

$(\Sigma \mathrm{y}) 2$ =Jumlah nilai Y kemudian dikuadratkan

\section{Uji Reliabilitas}

Reliabilitas berasal dari kata reliability. Ghozali (2009) menyatakan bahwa reliabilitas adalah alat untuk mengukur suatu kuesioner yang merupakan indikator dari peubah atau konstruksi. Suatu kuesioner dikatakan reliabel atau handal jika jawaban seseorang terhadap pernyataan adalah konsisten atau stabil dari waktu ke waktu. Reliabilitas suatu test merujuk pada derajat stabilitas, konsistensi, daya prediksi, dan akurasi. Pengukuran yang memiliki reliabilitas yang tinggi adalah pengukuran yang dapat menghasilkan data yang reliable.

Rumus

$$
r_{11}=\left(\frac{n}{n-1}\right)\left(1-\frac{\sum \sigma_{t}^{2}}{\sigma_{t}^{2}}\right)
$$




$\begin{array}{ll}\text { Keterangan : } & \\ \mathrm{r} 11 & =\text { Realibilitas yang dicari } \\ \mathrm{n} & =\text { Jumlah item pertanyaan yang diuji } \\ \sum \sigma_{\mathrm{t}}^{2} & =\text { Jumlah varians sko tiap-tiap item } \\ \sigma_{\mathrm{t}}^{2} & =\text { Varians total }\end{array}$

\section{Analisis Regresi Linier Sederhana}

Teknik analisis regresi linier sederhana adalah teknik yang digunakan peneliti dalam penelitian ini dengan menggunakan SPSS 23, tujuannya adalah untuk memudahkan peneliti dalam menganalisis pengaruh variabel kesejahteraan karyawan yang bersifat fasilitas dan turnover intention. Jika dirumuskan bentuk regresi sederhananya adalah sebagai berikut:

$$
\mathrm{Y}=\mathrm{a}+\mathrm{bX}
$$

\section{Keterangan:}

Y : Subjek variabel terikat yang di prediksi

a : Bilangan konstanta

b : Koefisien regresi

$\mathrm{X} \quad$ : Subjek variabel bebas yang mempunyai nilai tertentu

\section{Definisi Operasional Variabel}

Operasional variabel diperlukan guna menentukan jenis indikator dari variabel-variabel yang terkait dalam penelitian ini. Di samping itu, operasional variabel bertujuan untuk menentukan skala pengukuran dari masing-masing variabel, sehingga pengujian hipotesis dengan menggunakan alat bantu dapat dilakukan dengan tepat. Berikut rincian variabel dalam penelitian ini

a) Variabel kesejahteraan bersifat ekonomi ( $\mathrm{X}$ ) :

Tinggi rendahnya produktivitas kerja karyawan sangat menentukan kemampuan perusahaan dalam menjalankan usahanya dalam hal ini berarti upah dan tunjangan kesejahteraan karyawan adalah factor-faktor yang akan mempengaruhi produktivitas kerja. Penelitian ini bertujuan untuk mengetahui apakah pemberian upah dan tunjangan kesejahteraan karyawan memberikan pengaruh terhadap peningkatan produktivitas kerja karyawan pada perusahaan. 
b) Variabel turnoverintention ( Y ) :

Kesejahteraan bersifat ekonomi terhadap turnover intention yang tinggi biasanya disebabkan oleh minimnya program kesejahteraan karyawan. Komponen upah pekerjaan yang mana besarnya ditetapkan berdasarkan kesepakatan. atau gajih berdasarkan surat edaran menteri tenaga kerja republik Indonesia tahun (1990) gajih pokok adalah imbalan dasar yang dibayarkan oleh karyawan menurut tingkat.

\section{HASIL DAN PEMBAHASAN}

Dalam penelitian ini untuk mengetahui pengaruh kesejahteraan bersifat ekonomi terhadap turnover intention pada PT Arina Multikarya Samarinda, digunakan analisis rentang skala dengan menggunakan teknik interval dengan menggunakan keterangan sebagai berikut:

Tabel 2 :Skala Penilaian Interval

\begin{tabular}{ll}
\hline Sangat Kurang & $\mathbf{1 , 0 0}-\mathbf{1 , 7 9}$ \\
\hline Kurang & $1,80-2,59$ \\
Cukup & $2,60-3,39$ \\
Baik & $3,40-4,19$ \\
Sangat Baik & $4,20-5,00$ \\
\hline Sumber data $:$ Data Primer yang diolah (2019)
\end{tabular}

Pada instrumen uji validitas penelitian ini, terdapat sebanyak 5 pertanyaan untuk variabel kesejahteraan bersifat fasilitas dan 10 pertanyaan untuk variabel turnover intention dalam perhitungan validitas untuk variabel penelitian dilakukan dengan aplikasi SPSS23. Variabel penelitian dapat dikatakan valid jika nilai validitas yang diperoleh $r$ hitung $\geq 0,5$. Dapat dilihat pada tabel dibawah ini untuk hasil uji validitas variabel kesejahteraan bersifat fasilitas terhadap turnover intention pada PT. Arina Multikarya Samarinda adalah sebagai berikut:

Tabel 3 : Uji Validitas Variabel Kesejahteraan Yang Bersifat Ekonomi (X)

\begin{tabular}{|c|c|c|c|}
\hline No Data & Korelasi ( $\left.\mathrm{r}_{\text {hitung }}\right)$ & $\mathrm{R}_{\text {tabel }}$ & \multirow{2}{*}{ Keterangan } \\
\hline X1 & 0,634 & 0,1598 & \multirow{2}{*}{ Valid } \\
\hline X2 & 0,701 & 0,1598 & \\
\hline X3 & 0,715 & 0,1598 & \\
\hline X4 & 0,662 & 0,1598 & \\
\hline X5 & 0,506 & 0,1598 & \\
\hline
\end{tabular}

Sumber data : SPSS versi 23 
Tabel 4 : Uji Validitas Variabel Turnover Intention

\begin{tabular}{|c|c|c|c|}
\hline No Data & Korelasi ( $\mathrm{r}_{\text {hitung }}$ ) & $\mathrm{R}_{\text {tabel }}$ & Keterangan \\
\hline Y1 & 0,581 & 0,1598 & \multirow{10}{*}{ Valid } \\
\hline $\mathrm{Y} 2$ & 0,662 & 0,1598 & \\
\hline Y3 & 0,704 & 0,1598 & \\
\hline Y4 & 0,687 & 0,1598 & \\
\hline Y5 & 0,502 & 0,1598 & \\
\hline Y6 & 0,438 & 0,1598 & \\
\hline Y7 & 0,590 & 0,1598 & \\
\hline Y8 & 0,532 & 0,1598 & \\
\hline Y9 & 0,562 & 0,1598 & \\
\hline Y10 & 0,371 & 0,1598 & \\
\hline
\end{tabular}

Sumber data : SPSS versi 23

Tabel 5 : Hasil Uji Reliabilitas Penelitian

\begin{tabular}{|c|c|c|}
\hline Variabel & Cronbach's Alpha & Keterangan \\
\hline Ekonomi & 0,645 & \multirow{2}{*}{ Reliabel } \\
\hline Turnover Intention & 0,763 & \\
\hline
\end{tabular}

Sumber data : SPSS versi 23

Berdasarkan tabel di atas hasil uji reliabilitasdiketahui bahwa nilai Cronbach's Alpha lebih besar dari 0,6 untuk semua variabel, dapat disimpulkan bahwa dari kedua variabel yang ada merupakan pelatihan dan motivasi dinyatakan reliabel. 


\section{Hasil Analisis Regresi Sederhana}

Tabel 6 :Hasil Analisis Pengaruh Kesejehateraan Ekonomi Terhadap Turnover Intention Pada PT. Arina Multkarya Samarinda

\begin{tabular}{|l|l|l|l|}
\hline Variabel bebas & Koefesien Regresi & $\mathrm{t}$ hitung & $\begin{array}{l}\text { Probabilitas } \\
\text { (Sig. t) }\end{array}$ \\
\hline Ekonomi & 0,170 & 2,467 & 0,217 \\
\hline Konstanta & 29,653 & \\
F Hitung & 1,535 & \\
$\mathrm{R}^{2}$ & 0,010 & \\
Adjusted $\mathrm{R}^{2}$ & 0,004 & \\
$\mathrm{R}$ & 0,101 & \\
\hline \multicolumn{2}{|c|}{ Variabel Terkait Turnover Intention } \\
\hline
\end{tabular}

Dari hasil perhitungan analisis regresi sederhanatelah menunjukkan terdapat pengaruh antara variabel Kesejahteraan yang bersifat ekonomi terhadap turnover intention. Hal tersebut dilihat pada nilai koefisien determinasi (R2) yaitu sebesar 0,010. Demikian berarti ekonomi dipengaruhi oleh turnover intention sebesar 1\% sedangkan sisanya sekitar99\% dipengaruhi oleh variabelvariabel lain yang tidak termasuk dalam penelitian ini.

\section{Hasil Uji Hipotesis}

Untuk menguji apakah variabel kesejahteraan ekonomi mempunyai pengaruh yang signifikan terhadap variabelturnover intention atau tidak berpengaruh maka digunakan uji $\mathrm{t}$ (t-test), dengan cara membandingkan $t_{\text {hitung }}$ dengan $t_{\text {tabel }}$. Berdasarkan hasil analisis diperoleh nilai $t_{\text {hitung }}$ sebesar 2,467 lebih besar dari nilai $r_{\text {tabel }} 1,655$, dan nilai signifikan 0,217 >0,05 dan tingkat keyakinan 95\% $(\alpha=0,05)$, derajat kebebasan 151 diperoleh nilai $t_{\text {tabel }}$ sebesar 1,655, maka $t_{\text {hitung }}>t_{\text {tabel }}$. Dengan kata lain kesejahteraan ekonomi berpengaruh positif dan tidak signifikan. Dengan turnover intention pada perusahaan. Ho ditolak Ha diterima, berdasarkan uji t tersebut maka dapat disimpulkan bahwa terdapat pengaruh positif kesejahteraan ekonomi terhadap turnover intention. Kurva uji t pada penelitian ini dapat dilihat pada gambar, berikut: 


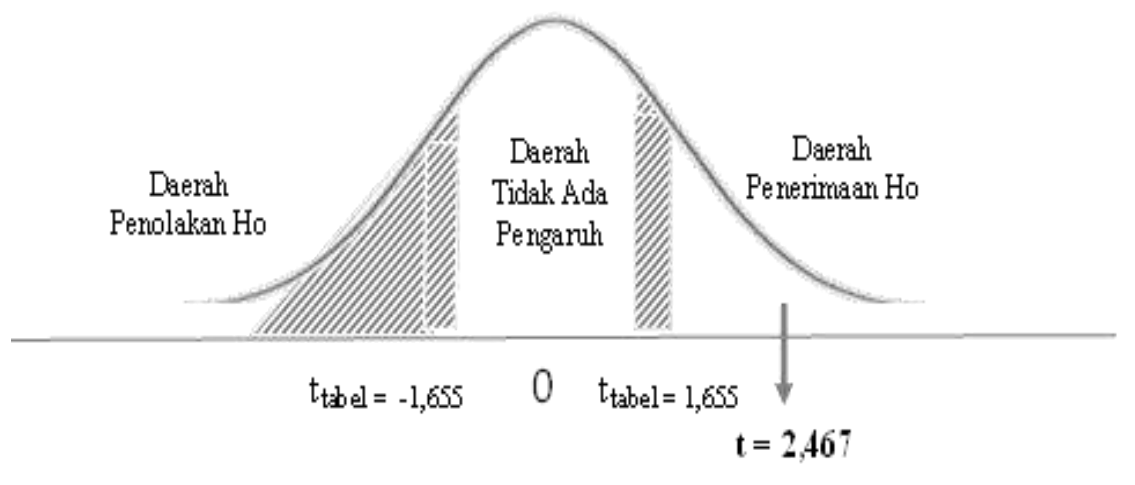

Gambar 2 :Gambar Kurva Uji T

Berdasarkan hasil uji hipotesis dengan menggunakan uji t, maka dapat disimpulkan bahwa:

Ho :Ekonomi mempunyai pengaruh yang tidak signifikan terhadap Turnover Intention pada PT.Arina Multikarya Samarinda.

Ha : Ekonomi mempunyai pengaruh yang signifikan terhadap Turnover Intention pada PT.Arina Multikarya Samarinda.

Dinyatakan valid karena $t_{\text {hitung } 2,467}$ lebih besar dari $t_{\text {tabel }} \mathbf{1 , 6 5 5}$

\section{Pembahasan}

Berdasarkan hasil rata-rata skor keseluruhan untuk variabel ekonomi dengan lima pernyataan yaitu 3,61 berada pada rentang kategori skor 3,40 - 4,19 atau berada pada kategori baik. Kondisi ini menunjukkan bahwa karyawan PT Arina Multikarya memiliki Ekonomi yang baik pada perusahaannya. Karyawan yang merasa cukup dengan ekonomi yang diberikan oleh perusahaan akan menunjukkan sikap positif dan baik terhadap kinerja seorang karyawan. Hal ini akan terlihat dari sikap karyawan dalam melakukan pekerjaannya, karyawan dengan tingkat ekonomi yang baik dapat memberikan kinerja yang baik, mulai dari penuntasan kerja dengan baik, kehadiran dan peningkatan prestasi kerja dengan baik. Sebaliknya, jika karyawan yang tidak ditunjang dengan fasilitas yang baik akan menurunkan minat kerja dan karyawan dapat berpotensi meninggalkan perusahaan.

Berdasarkan dari hasil perhitungan menggunakan analisis regresi sederhana yang dilakukan yaitu terdapat pengaruh antara variabel Ekonomi terhadap variabel Turnover intention.

Berdasarkan hasil rata-rata skor keseluruhan untuk variabel Turnover Intention dengan 10 pernyataan yaitu 3,27 berada pada rentan skor 2,60 - 3,39 atau berada pada kategori cukup. Kondisi ini menunjukan bahwa intensi keluar masuk karyawan yang ada pada PT. Arina Multikarya cukup tinggi.

\section{SIMPULAN}

Peningkatan Turnover Intention dipengaruhi oleh ekonomi. Diketahui bahwa jika tingkat Ekonomi yang baik maka akan berpengaruh terhadap Turnover Intention. Hal ini ditunjukkan setelah diolah dengan menggunakan regresi linier sederhana, berdasarkan hasil persamaan regresi tersebut dapat dijelaskan bahwa Turnover Intention karyawan sebesar 29,653. Artinya semakin tinggi ekonomi kerja maka akan jadi semakin tinggi juga semangat kerja karyawan sehingga memperkecil dampak Turnover Intention. Tingkat turnover yang tinggi dapat menimbulkan dampak negatif bagi organisasi, hal ini seperti menciptakan ketidakstabilan dan 
ketidakpastian (uncertainty) terhadap kondisi tenaga kerja dan peningkatan biaya sumber daya manusia yakni yang berupa biaya pelatihan yang sudah didivestasikan pada karyawan sampai biaya recruitment dan pelatihan kembali.

\section{DAFTAR PUSTAKA}

Alex Bayu Sahari. 2009, Pengaruh Kompensasi Non Finansial Terhadap Motivasi Kerja Karyawan Di Perusahaan Rodeo - Lawang.

Amelia. 2010. Work-To-Family Conflict Dan Family-To-Work Conflict Terhadap kepuasaan Dalam Bekerja, Keinginan Pindah Tempat Kerja Dan Kinerja Karyawan. Jakarta: RajaGrafindo Persada

Azwar. 2011, Reliabilitas Dan Validitas. Yogyakarta : Pustaka Pelajar.

Fajar Wahyu Utomo.2013, Pengaruh Infalsi Dan Upah Terhadap Pengangguran Di Indonesia, Jakarta: Bina Aksara.

Ghozali. 2009, Pengantar Manajemen Dan Masalah. BPA UGM, Bulletin no. 1.

Handoko. 2012. Motivasi dan Pemotivasian dalam Manajemen. Jakarta: Raja Grafindo Persada.

Ni Nyoman Setya Ari Wijayanti, Ni Luh Karmini. 2014. Pengaruh Tingkat Inflasi, Laju Pertumbuhan Ekonomi Dan Upah Minimum Terhadap Tingkat Pengangguran Terbuka Di Provinsi Bali.

Puspitasari.2012, Pengaruh Konflik Pekerjaan Keluarga Terhadap Komitmen Organisasi Dengan Kepuasan Kerja. Jakarta.

Rivai. 2009, Pengaruh Kepuasaan Kerja terhadap Turnover Intention Karyawan Non Manajerial. PT Multigruop Logistic. Jakarta.

Ronald dan Milkha, 2014 Job Satisfaction, Turnover Intention, MSQ. Jakarta.

Sakarno. 2013, Manajemen Sumber Daya Manusia: Dasar dan Kunci Keberhasilan, Jakarta: PT. Bumi Aksara.

Samuel dan Ikemefuna. 2012, Hubungan Antara Sistem Kompensasi dengan Intensi Turnover Karyawan Rumah Sakit Tugu Ibu. Depok.

Siagian, 2012, Pengaruh Kepuasaan Kerja Terhadap Intensi Turnover Karyawan di Indonesia, Jakarta: Ekonomi. 
Sugiyono. 2010, Meningkatkan Komitmen dan Kepuasaan untuk Menyurutkan Niat Keluar. Dalam Jurnal Manajemen dan Kewirausahaan.Vol. 11, No.2. Jakarta.

Yuniarsih dan Suwanto. 2011. Paradigma Baru Manajemen Sumber Daya Manusia. Yogyakarta: Amara Books 